\title{
INTRAOPERATIVE ULTRASOUND EXAMINATION OF HILAR CHOLANGIOCARCINOMA /TUMOR OF KLATSKIN /
}

\author{
Ivailo P. Vazharov ${ }^{1}$, Daniel V. Kostov ${ }^{2}$ \\ 1) Department of Gastroenterology, 2) Department of Surgery, \\ Multiprofile Hospital for Active Treatment - Varna, \\ Military Medical Academy - Sofia, Bulgaria
}

\begin{abstract}
:
Purpose: To compare the opportunities of the intraoperative ultrasound examination of the liver with the preoperative imaging methods - Computer tomography (CT), Ultrasound examination (US) in detecting hepatic lesions in patients with tumor of Klatskin (hilar cholangiocarcinoma).

Patients and methods: This is a prospective study of 7 patients, which had undergone open operative intervention for tumor of Klatskin. The affecting of the liver by the tumor process was examined preoperatively with Ultrasound examination and Computer tomography with contrast amplification, and by inspection and palpation and intraoperative ultrasound during the operative intervention.

Results: The maximum numbers of malignant lesions are found by IOUS - totally 21 . Preoperative ultrasound found 5 lesions or $23,80 \%$ of the maximum number and preoperative CT -9 or $33,33 \%$. The information from IOUS changed the operative plan in $2 / 7$ of the patients $(28,57 \%)$. A biliary stent was placed under the control of IOUS in one patient with a heavy hyperbilirubinemia - 791,6 $\mu \mathrm{mol} / \mathrm{l}$.

Conclusions: IOUS is significantly helpful in surgery of tumor of Klatskin. Besides the precise localization and staging of the tumor the information of IOUS changes the surgical strategy in some patients.
\end{abstract}

Key words: preoperative ultrasound, Computer tomography, intraoperative ultrasound, tumor of Klatskin.

\section{INTRODUCTION:}

After the hepatocellular carcinoma, the cholangiocellular carcinoma (CC) is the second most common primary malignant liver tumor.(10) The greater part $-60-70 \%$ of $\mathrm{CC}$ is found in the bifurcation of the biliary ducts and is known as Tumor of Klatskin or hilar (as well as peri hilar) cholangiocarcinoma.(3) The most popular classification of the localization of tumor of Klatskin is the one of Bismuth-Corlette.(4) According to the latter Type I affects the common biliary duct, type II - the common biliary duct and the connection of the left and right biliary duct, type IIIA - the common biliary duct, biliary connection and the right biliary duct, IIIB - common biliary duct, biliary connection and the left biliary duct, type IV - common biliary duct, biliary connection, the right and left biliary ducts or multifocal tumor of the bile ducts.(see fig. 1)(5)

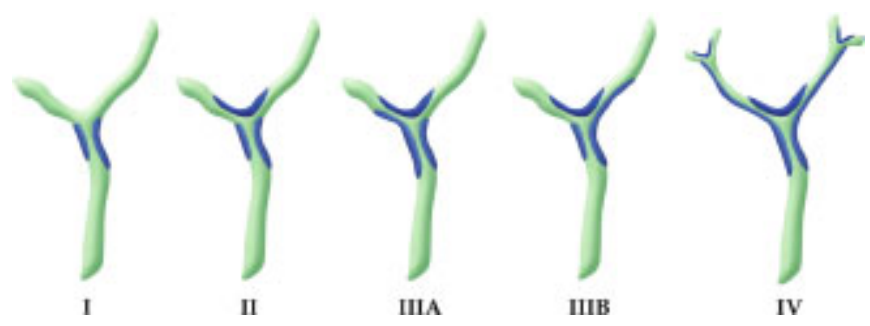

Fig. 1. Illustration of the classification of BismuthCorlette of tumor of Klatskin

The classification of Bismuth-Corlette does not exclude the TNM classification, which must complement the diagnosis. The current $7^{\text {th }}$ issue of the classification is published in 2009 and comes into effect in 2010.(6) By reason of their localization these tumors present symptoms in their final stages and they are not resectable when they are diagnosed.(7)

\section{PATIENTS AND METHODS APPLIED:}

In our study we had 9 patients -6 men and 3 women, which had undergone open operative intervention for tumor of Klatskin (hilar cholangiocellular carcinoma) for the period $2007-2010$. The average age of the patients was 61 years, the minimum one -36 years, and the maximum -71 years.

The patients were classified according to the classification of Bismuth - Corlette as follows:

Klatskin type I - none

Klatskin type II - four patients

Klatskin type IIIA - one patient

Klatskin type IIIB - one patient

Klatskin type IV - one patient .

Two of the patients are operated for tumor of Klatskin - one of them 4 months ago and the other 2 years ago and now they have metastases of the carcinoma. 
The liver was examined preoperatively by US and CT with contrast amplification and with inspection and palpation and IOUS during the operative intervention.

The examination was approved by the ethical committee of MHAT - Varna of MMA, and all the patients have signed an informed consent before the examinations and the operation. All the procedures are in conformity with the Good clinical practice and ethical standards of World medical association (Declaration from Helsinki for the rights of the examined patients).

\section{RESULTS:}

The maximum number of the malignant liver lesion (MLL) are found by IOUS and they are totally 21.(fig. 2) All they are confirmed histologically. Only 5 lesions detected with the help of the preoperative ultrasound or $23,80 \%$ of the maximum number, this percent reaches $33,33 \%$ with the help of preoperative CT.

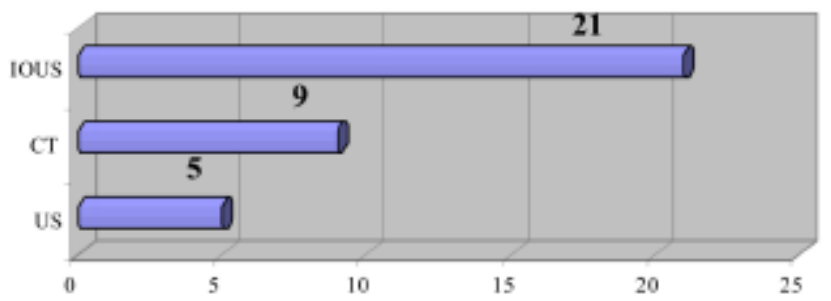

This is due to detection of lesions under $20 \mathrm{~mm}$, IOUS founds 6 lesions against 2 from $\mathrm{CT}$ and 0 lesions from US. From 20 to $30 \mathrm{~mm}$ - IOUS detects 11 lesions, CT only 3 , and US doesn't find any lesions. Over $30 \mathrm{~mm}$ - the results of the imaging modalities equalize. / fig. 3/

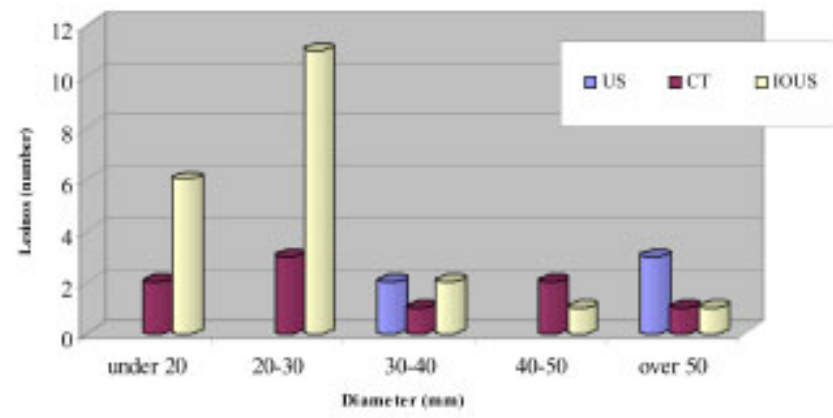

Fig. 3. The distribution of the MLL in patients with tumor of Klatskin according to their diameter and method of graphic diagnostics.

These results may be explained with the structural non homogeneity in the region of the hepatic hilus, having in mind that most of the lesions are found in IV and V segment, as seen in table 1 .

Fig. 2. Number of the malignant lesions of the tumor of Klatskin according to the method of diagnostics.

\begin{tabular}{|c|c|c|c|c|c|c|c|c|c|}
\hline \multirow{2}{*}{$\begin{array}{c}\text { Method of } \\
\text { diagnostics }\end{array}$} & \multicolumn{8}{|c|}{ Tumor of Klatskin } & \multirow{2}{*}{$\begin{array}{c}\text { Total number } \\
\text { of MLL }\end{array}$} \\
\hline & I & II & III & IV & $\mathbf{V}$ & VI & VII & VIII & \\
\hline US & - & - & - & 3 & 2 & - & - & - & 5 \\
\hline CT & - & 1 & 2 & 3 & 1 & 1 & 1 & - & 9 \\
\hline IOUS & - & 2 & 3 & 9 & 1 & 2 & 1 & 3 & 21 \\
\hline
\end{tabular}

Table 1. MLL in patients with tumor of Klatskin according to the methods of diagnostics and segments of the liver.

The results of tumor of Klatskin according to the ultrasound type of MLL and method of graphic diagnostics are represented in table 2 .

\begin{tabular}{|c|c|c|c|c|c|c|}
\hline \multirow{2}{*}{$\begin{array}{c}\text { Method of } \\
\text { diagnostics }\end{array}$} & \multicolumn{5}{|c|}{ Total number according to the ultrasound type } & \multirow{2}{*}{$\begin{array}{c}\text { Total } \\
\text { number } \\
\text { of MLL }\end{array}$} \\
\cline { 2 - 6 } & $\begin{array}{c}\text { Hyper- } \\
\text { echogenic }\end{array}$ & $\begin{array}{c}\text { Hypo- } \\
\text { echogenic }\end{array}$ & $\begin{array}{c}\text { Mixed } \\
\text { echogenic }\end{array}$ & $\begin{array}{c}\text { Iso- } \\
\text { echogenic }\end{array}$ & „Buffalo eye" & $\mathbf{5}$ \\
\hline US & 3 & 1 & 1 & & 1 & $\mathbf{2 1}$ \\
\hline IOUS & 18 & 1 & 1 & 1 & & $\mathbf{5}$ \\
\hline
\end{tabular}

Table 2. Distribution according to the number and ultrasound appearance of MLL and method of graphic diagnostics in tumor of Klatskin. 
On fig. 4 IOUS of hypoechogenic tumor of Klatskin is presented, and dilated intrahepatic biliary ducts above it. On fig. 5 a hyperechogenic variant of the tumor, and on fig. 6 - colour Doppler shows the hyper vascularization of the tumor of Klatskin.

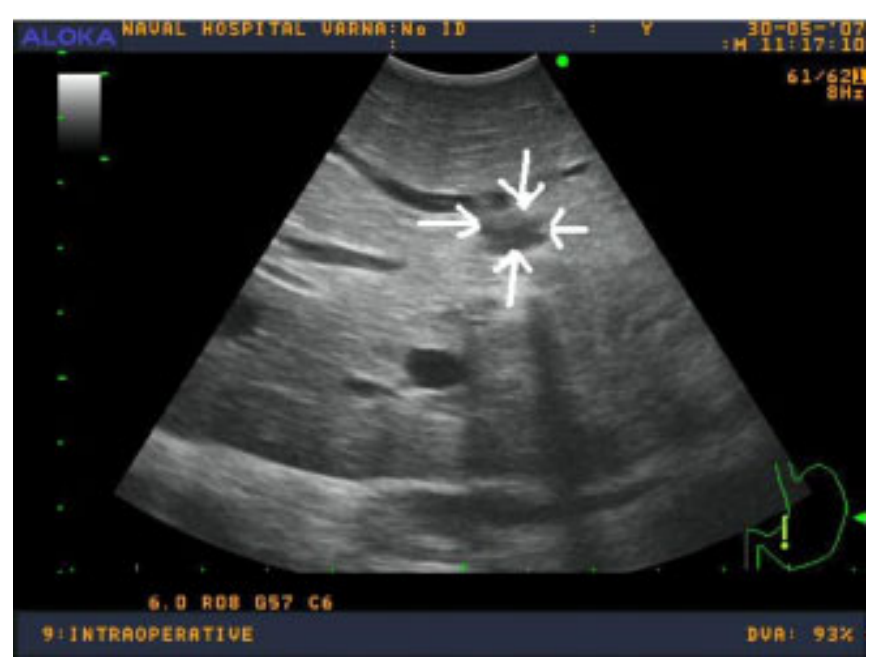

Fig. 4. IOUS - Tumor of Klatskin with dilated intrahepatic biliary ducts.

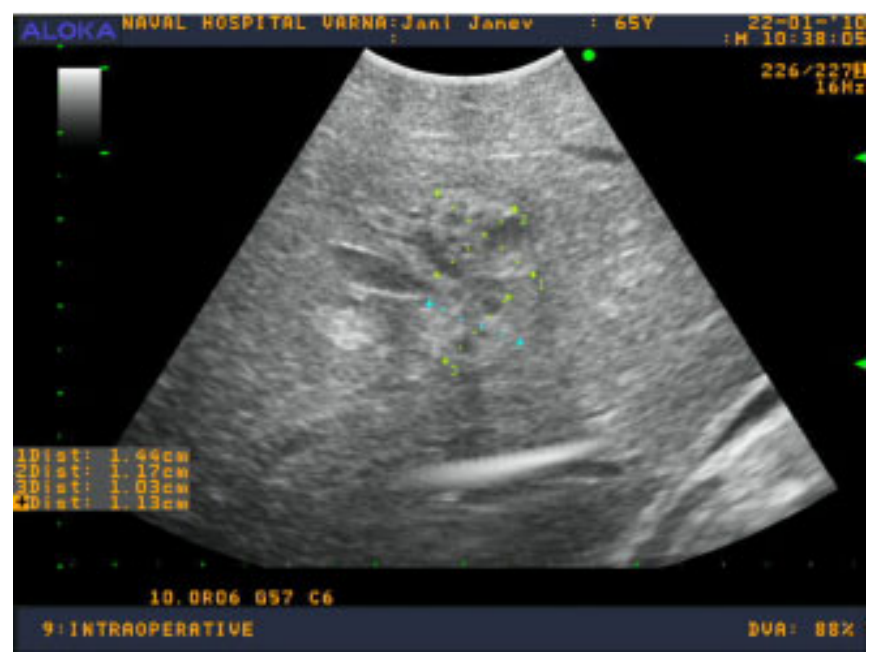

Fig. 5. IOUS - tumor of Klatskin-- type IIIA

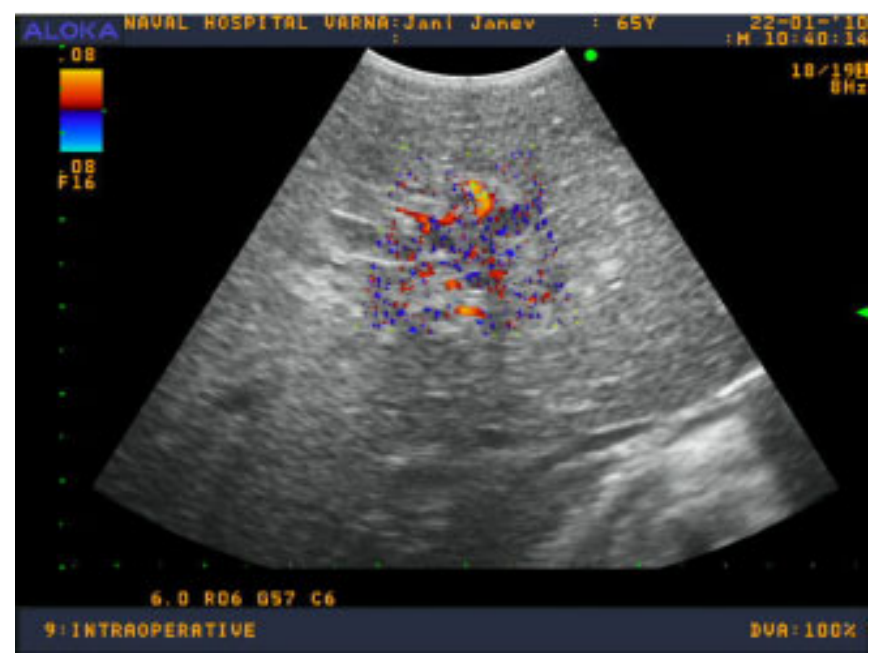

Fig. 6. IOUS with colour Doppler - the good vascularization of the tumor is seen.

A stent was placed under ultrasound control in one patient with mechanical icterus and bilirubin in serum $791,6 \mu \mathrm{mol} / 1$.

\section{DISCUSSION:}

The prognosis of untreated hilar cholangiocarcinoma is serious, with average survival rates less than 3 months. Its operative treatment is a complex problem. The removal of the tumor through local excision, combined with hepatic parenchymal resection or palliative operative biliary decompression is complicated with the anatomical variations of the region and sometimes atrophic-hypertrophic changes in the liver, in response to obstruction in the biliary system.(8)The preoperative assessment of the respectability of the tumor is important.(9) US and CT are sensitive methods confirming the dilatation of the biliary ducts, localization of the place of obstruction and excluding biliary stones.(10)

We had 9 patients who had undergone operative intervention on the occasion of tumor of Klatskin. The most affected age was between 60 and 70 years. Most common is Klatskin type II - 4 patients, Klatskin type IIIA - 1 patient, III B - one patient and IV - one patient, type I - none.

IOUS found 21 lesions -4 times more than US (5 lesions) and 2 times more than CT (9 lesions). This is due to the small diameter of the lesions of tumor of Klatskin. US doesn't detect lesions under $30 \mathrm{~mm}$, CT found 5 lesions compared to 17 by IOUS. Another reason is the structural non homogeneity of the confluence which hampers detection of small tumors. The average diameter of the lesions found by US is $47 \mathrm{~mm}$, CT $-44,09 \mathrm{~mm}$, IOUS $-30,50 \mathrm{~mm}$.

Regarding the characterization, the lesions found by IOUS are predominantly hyper echogenic -18 , one lesion with mixed echogenicity, iso- and hypo-echogenicity. We did 
not find information regarding the characterization of the echogenicity of the lesions of tumor of Klatskin by IOUS in the literature. We localized them with IOUS, the most common localization was IV segment with 9 / 21 lesions / $42,85 \%$ /. Vascular invasion was not found. A biliary stent was placed under IOS control in one patient with a heavy hyper bilirubinemia - 791,6 $\mu \mathrm{mol} / \mathrm{l}$. with respect to histology the tumor of Klatskin in our study was predominantly low differentiated adenocarcinoma. The information from IOUS changed the operative plan in $2 / 7$ of the patients $/ 28,57 \% /$.

\section{CONCLUSIONS:}

IOUS is significantly helpful in surgery of tumor of Klatskin. Besides the precise localization and staging of the tumor the information of IOUS changes the surgical strategy in some patients.

\section{REFERENCES:}

1. Friman S. Cholangiocarcinomacurrent treatment options. Scand J Surg. 2011; 100(1):30-34. [PubMed]

2. Jang HJ, Kim TK, Wilson SR. Imaging of malignant liver masses: characterization and detection. Ultrasound Q. 2006 Mar;22(1):19-29. [PubMed]

3. Choi JY, Kim MJ, Lee JM, Kim KW, Lee JY, Han JK. et al. Hilar cholangiocarcinoma: role of preoperative imaging with sonography, MDCT, MRI, and direct cholangiography. AJR Am J Roentgenol. 2008 Nov;191(5):1448-57. [PubMed] [CrossRef]

4. Bismuth H, Colette MB: Intrahepatic cholangioenteric anastomosis in carcinoma of the hilus of the liver. Surg Gynaecol Obstet. 1975 Feb;140(2):170-

\section{8. [PubMed]}

5. Sainani NI, Catalano OA, Holalkere NS, Zhu AX, Hahn PF, Sahani DV. Cholangiocarcinoma: current and novel imaging techniques. Radiographics. 2008 Sep-Oct;28(5):1263-87. [PubMed] [CrossRef]

6. Union for International Cancer Control/ (UICC): TNM Classification of malignant tumours, 7 th Edition. November 2009, Wiley-Blackwell ISBN: 978-1-4443-3241-4

7. de Jong MC, Hong SM, Augustine MM, Goggins MG, Wolfgang CL, Hirose K, et al. Hilar cholangiocarcinoma: tumor depth as a predictor of outcome. Arch Surg. 2011 Jun; 146(6): 697-703. [PubMed]

8. Vazharov I. Opportunities of intraoperative ultrasound in malignant liver lesions. Author's summary of his dissertation. 2011: 23-25. http://vma.bg/ doc/proceduri/Vazharov/Avtoreferat.pdf [in Bulgarian]

9. Kaiser GM, Sotiropoulos GC, Sgourakis G, Bleck J, Baba HA, Beckebaumr S, et al. Surgical treatment of Klatskin tumor: liver resection versus transplantation. Hepatogastroenterology. 2010 Nov-Dec;57(104):1337-40. [PubMed]

10. Ramos Rubio E. Radical surgery for hilar cholangiocarcinoma (Klatskin tumor) [Article in Spanish] Cir Esp. 2007 Jul; 82(1):11-5. [PubMed]

11. Ito F, Cho CS, Rikkers LF, Weber SM. Hilar cholangiocarcinoma: current management. Ann Surg. 2009 Aug; 250(2):210-8. [PubMed] [CrossRef]

\section{Corresponding author:}

Ivailo P. Vazharov

Multiprofile Hospital for Active Treatment - Varna, Military Medical Academy,

84, Oditel str., Varna, Bulgaria

E-mail: vajarov@dir.bg 